\title{
Cabin air temperature of parked vehicles in summer conditions: life-threatening environment for children and pets calculated by a dynamic model
}

\author{
Johannes Horak $^{1,2}$ • Ivo Schmerold ${ }^{3}$ • Kurt Wimmer ${ }^{1}$ • Günther Schauberger ${ }^{1}$ (D)
}

Received: 18 March 2016/Accepted: 24 June 2016 /Published online: 18 July 2016

(C) The Author(s) 2016. This article is published with open access at Springerlink.com

\begin{abstract}
In vehicles that are parked, no ventilation and/or air conditioning takes place. If a vehicle is exposed to direct solar radiation, an immediate temperature rise occurs. The high cabin air temperature can threaten children and animals that are left unattended in vehicles. In the USA, lethal heat strokes cause a mean death rate of 37 children per year. In addition, temperature-sensitive goods (e.g. drugs in ambulances and veterinary vehicles) can be adversely affected by high temperatures. To calculate the rise of the cabin air temperature, a dynamic model was developed that is driven by only three parameters, available at standard meteorological stations: air temperature, global radiation and wind velocity. The transition from the initial temperature to the constant equilibrium temperature depends strongly on the configuration of the vehicle, more specifically on insulation, window area and transmission of the glass, as well as on the meteorological conditions. The comparison of the model with empirical data showed good agreement. The model output can be applied to assess the heat load of children and animals as well as temperature-sensitive goods, which are transported and/or stored in a vehicle.
\end{abstract}

This paper is dedicated to Prof. Dr. Gertrud Keck, former head of the Institute of Medical Physics and Biostatistics, on the occasion of her 90th birthday.

Günther Schauberger

gunther.schauberger@vetmeduni.ac.at

1 WG Environmental Health, Unit for Physiology and Biophysics, University of Veterinary Medicine Vienna, Veterinärplatz 1, A 1210 Vienna, Austria

2 Present address: Institute of Atmospheric and Cryospheric Sciences, University of Innsbruck, Innsbruck, Austria

3 Institute of Pharmacology and Toxicology, University of Veterinary Medicine Vienna, Veterinärplatz 1, A 1210 Vienna, Austria
Keywords Cabin air temperature $\cdot$ Vehicle $\cdot$ Heat stroke Child $\cdot$ Animal $\cdot$ Summer time

\section{Introduction}

In modern vehicles, heating, ventilation and air conditioning (HVAC) systems are in used to maintain the thermal comfort and air quality inside of the driver cabin while the vehicle is in operation. Besides this continuous operating state, the HVAC must reach a steady state corresponding to the aspired comfort level in a reasonable time after the start of operation. The heating power for a vehicle lies in the range $5-10 \mathrm{~kW}$ for an outside temperature of $-20{ }^{\circ} \mathrm{C}$, the cooling power (evaporator performance) 3-7 kW (DIN 1946-3 2006). Even if the vehicle is only ventilated by fans or by wind pressure due to its velocity, the air mass flow rate reaches $4-10 \mathrm{~kg} \mathrm{~min}^{-1}\left(0.067-0.167 \mathrm{~kg} \mathrm{~s}^{-1}\right)$ (Böttcher and Konz 2011) and an air exchange rate between 2 and $60 \mathrm{~h}^{-1}$ (Fruin et al. 2011). Studies have investigated the thermal comfort in cabins of operated vehicles (e.g. Alahmer et al. 2011; Kaynakli et al. 2005; Liu and Zeng 2012).

If a vehicle is parked and the motor is turned off, then neither ventilation nor heating or cooling takes place. The air exchange rate of the cabin of parked passenger vehicles was determined to lie between 0.01 and $0.69 \mathrm{~h}^{-1}$ (Rugh et al. 2007; Zhang et al. 2008). Especially if the vehicle is exposed to direct solar radiation, it performs comparable to a greenhouse. Some studies have analysed cabin temperature in this context. Due to the vehicle's exposure to the meteorological situation, the thermal environment transforms towards a thermal steady state, described by a constant equilibrium temperature.

If the sensible energy balance is dominated by the incoming solar radiation, the temperature inside the vehicle stabilises within a range between 20 and $35 \mathrm{~K}$ above the outside temperature (Gibbs et al. 1995; Gregory and Constantine 1996; 
Grundstein et al. 2009; Jascha and Keck 1984; King et al. 1981; McLaren et al. 2005; Roberts and Roberts 1976; Surpure 1982). Marty et al. (2001) even found a temperature difference of close to $60 \mathrm{~K}$. As a rough estimation, they assessed the inside surface temperature due to solar radiation reaching $30^{\circ} \mathrm{C}$ for winter, $60{ }^{\circ} \mathrm{C}$ for spring and autumn and up to $90{ }^{\circ} \mathrm{C}$ during summer.

Grundstein et al. (2009) developed simple models to calculate the equilibrium temperature of vehicles as a function of the outside air temperature, the irradiance of solar radiation, as well as cloud cover. In the majority of cases, a value close to the equilibrium temperature is reached about 20-60 min after the cessation of ventilation.

As long as the vehicle is not occupied or transporting thermally sensitive cargo, this is of no concern. However, in rare cases, children and pets are left unattended in parked vehicles. The cabin temperature can then pose a dramatic threat to occupants, which may result in a heat stroke and subsequent death. Not only passengers, in particular children, and pets are threatened by the thermal conditions but also temperature-sensitive goods. Drugs, for instance, which are transported by ambulances and vehicles of veterinarians, have a limited shelf life, are temperature-sensitive, and must be stored under specific thermal conditions. For vehicles of veterinary practitioners, the thermal storage conditions have recently been investigated by Haberleitner et al. (2014) and Ondrak et al. (2015). The measurements show that, depending on the storage conditions, the upper temperature thresholds of drugs were exceeded frequently.

The harsh environment inside parked vehicles can cause heat stroke as a life-threatening syndrome observed in human and animals. It may result from exposure to environmental heat stress and is characterised by body core temperatures of $>40{ }^{\circ} \mathrm{C}$ in a human (Grundstein et al. 2015a; Grundstein et al. $2015 \mathrm{~b}$ ) and $>41{ }^{\circ} \mathrm{C}$ in dogs, as well as by central nervous system dysfunction (Bruchim et al. 2009). Not only is the heat stress relevant but also the duration of exposure (Shapiro et al. 1978).

In the USA, lethal heat strokes inside vehicles cause a mean death rate of 37 children per year (1998-2015) (McLaren et al. 2005; Null 2012). The annual mean death rate shows the distinct influence of latitude, with the maximum in the southwest states with 3.90 children per 100,000 (Grundstein et al. 2011). While the highest rates occur in southern regions and the lowest in northern regions, the latter still show death rates of about $1 / 3$ of that in southern states. The characteristics of these deaths were analysed by several investigations, in sum more than 800 cases (Booth et al. 2010; Grundstein et al. 2011; Guard and Gallagher, 2005). The death rate of children left in vehicles is up to half of all injury-related deaths in the USA: 8.5/100,000 in 2005 (Booth et al. 2010).

The death of animals, predominantly dogs, due to heat stroke in vehicles is not well documented (Gregory and
Constantine 1996; Shannon Flournoy et al. 2003). In such cases, the owners are charged under the relevant jurisdiction specific law for animal protection.

The aim of this paper was the development of a dynamic model for the cabin temperature driven by the three meteorological parameters: outdoor temperature, solar radiation and wind velocity, all of which are available on an hourly basis at standard meteorological stations. Due to the dynamic characteristics of the presented model, the time course of the cabin air temperature can be calculated as a proxy to evaluate the heat stress of humans and animals, taking into account the exposure time. Especially for forensic purposes, this approach can help to quantify whether a heat load has had the potential to cause a heat stroke, notably in lethal cases. To assess the thermal load onto an organism (humans as well as animals), the presented dynamic model has to be linked with a model that considers the metabolic energy production and the energy release of the body (Alahmer et al. 2011). Then, the time course of the body core temperature can be determined, which is a crucial parameter to assess the incidence of a lethal heat stroke.

\section{Materials and methods}

\subsection{Dynamic model for calculating the cabin temperature}

The cabin air temperature $\Theta_{\text {Air }}$ is calculated by a dynamic model taking into account the sensible energy fluxes from the transparent $\Phi_{\mathrm{T}}$ and opaque $\Phi_{\mathrm{O}}$ elements of the cabin and by the HVAC system $\Phi_{\mathrm{V}}$. Inside the cabin, passenger, animal or other energy release components $\Phi_{\mathrm{I}}$ are considered. Figure 1 gives an overview of the involved energy fluxes.

The change rate of the vehicle's cabin air temperature $\Theta_{\text {Air }}$ is calculated by the sensible heat balance

$c m \frac{d \Theta_{\mathrm{Air}}}{d t}=\Phi_{\mathrm{T}}+\Phi_{\mathrm{O}}+\Phi_{\mathrm{I}}+\Phi_{\mathrm{V}}$

with the air's mass $m$ and the thermal heat capacity $c$. Generally, the latent energy balance (humidity) can be neglected because no free water is available inside the vehicle for evaporation. Under the assumption that no water vapour source is inside the vehicle, the water vapour pressure will be the same outside and inside.

In the case of a parked vehicle with an inactive HVAC system, the resulting heat flux $\Phi_{\mathrm{V}}$ can be reduced to the natural air exchange, which is negligible if the windows are closed.

Opaque and transparent elements constitute the body of a vehicle. Their inner and outer surfaces are subject to heat transfer via convection $K$, the sun's short-wave radiation $R_{\mathrm{S}}$ and thermal radiation $R_{\mathrm{L}}$. 
Fig. 1 Sensible energy balance of a parked vehicle by convection $K$, short-wave $R_{\mathrm{S}}$ and long-wave thermal $R_{\mathrm{L}}$ radiation. Energy exchange between the vehicle body or objects within its interior and the cabin air occurs through convective heat fluxes $\Phi=A K$ where $A$ is the area of the interface with the cabin air. Inside the cabin, the sensible heat flux of a passenger, animal or component $\Phi_{\mathrm{I}}$ is shown. For a parked vehicle, the heat flux caused by the HVAC system or by natural air exchange $\Phi_{\mathrm{V}}$ is neglected

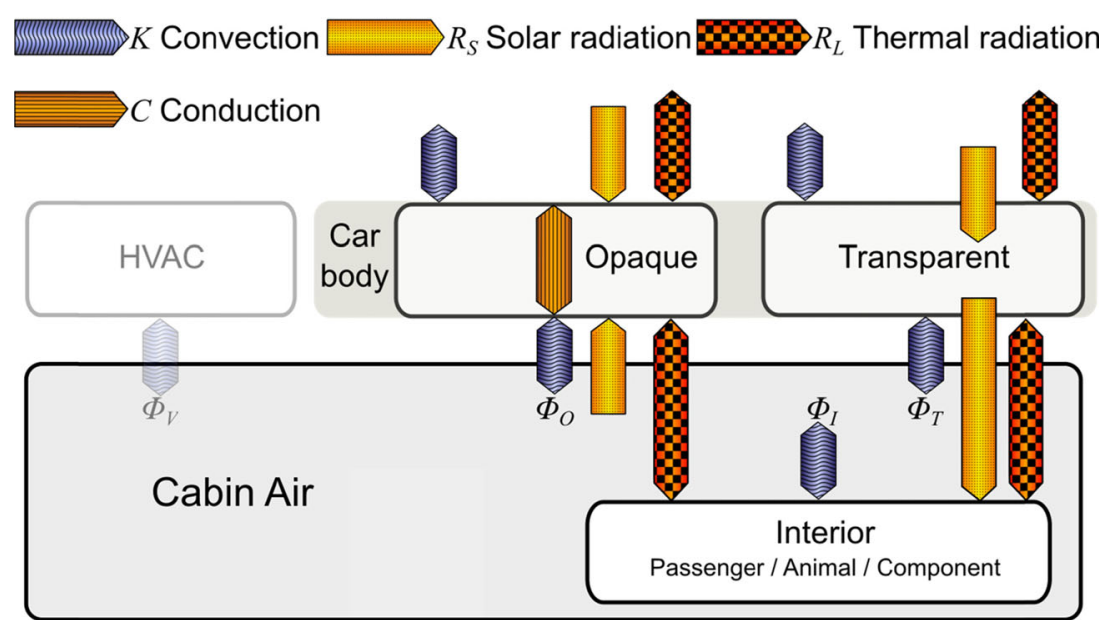

Air is mostly transparent to solar and thermal radiation; therefore, the only heat transfer mechanism leading to a change in cabin air temperature is convection $K$. The heat flux density $K$ between a surface of temperature $\Theta_{\mathrm{S}}$ and adjacent air is given by $K=\alpha_{\mathrm{K}}\left(\Theta_{\mathrm{A}}-\Theta_{\mathrm{S}}\right)$ with the air temperature $\Theta_{\mathrm{A}}$ and the convective heat transfer coefficient $\alpha_{\mathrm{K}}$ which is a function of the wind speed $v_{\mathrm{w}}$, given by $\alpha_{\mathrm{K}}=2.8+3 v_{w}$ (Wattmuff et al. 1977). On the interior, $v_{\mathrm{W}}=0 \mathrm{~m} / \mathrm{s}$ is assumed, corresponding to free convection.

The incoming solar short-wave radiation on an inclined surface $R_{\mathrm{S}}$ is calculated from the global radiation $G_{\mathrm{h}}$ (meteorological input parameter) on a horizontal receiving surface.

Obstructions above the geometric horizon affecting shortand long-wave radiation, such as buildings, are taken into account by defining a horizon heightening function $\gamma_{\mathrm{H}}(\alpha)$

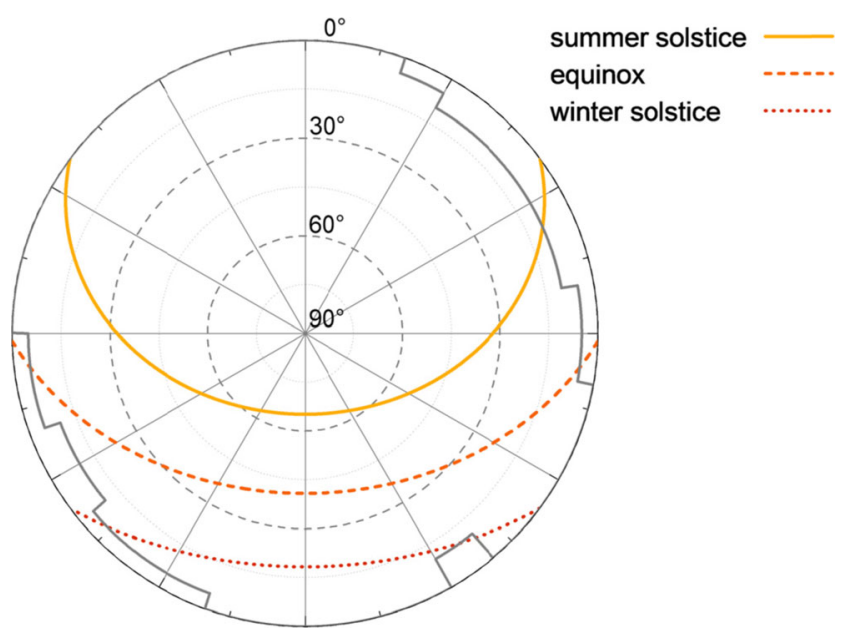

Fig. 2 Polar plot of the horizon heightening corresponding to one of the measurement sites and the sun's path at different times during a year. Values greater than zero correspond to buildings while smaller values (not shown) represent a lowered horizon due to an elevated position. The sun path is plotted for Vienna, Austria $\left(48^{\circ} \mathrm{N}, 16^{\circ} \mathrm{E}\right)$ for the winter and summer solstices and the equinox (September 23 and March 21, respectively) with $\alpha$ as the azimuthal angle. Values $\gamma_{\mathrm{H}}(\alpha)>0$ then correspond to the angular height of surrounding obstacles. If $\gamma \leq \gamma_{\mathrm{H}}(\psi)$, with $\psi$ as the sun's azimuthal angle and $\gamma$ as the sun's elevation angle, direct solar radiation is blocked (Fig. 2).

Transparent elements (e.g. windows) transmit a fraction $\tau_{\mathrm{S}}$ $\left(1-\rho_{\mathrm{S}}\right)$ of $R_{\mathrm{S}}$ to the vehicle's interior where it contributes to the heating of inside components as well as passengers and animals. Here, $\tau_{\mathrm{S}}$ and $\rho_{\mathrm{S}}$ are the coefficients of transmission and reflection, respectively; typical values are shown in Table 1.

Typical optical properties of surfaces with regard to shortwave and long-wave radiation are listed in Table 1. Metallic colours, consisting of small metal particles oriented parallel to the surface underneath, are approximated by assuming a mixture of $1 / 3$ coloured paint and $2 / 3$ aluminium flakes with $\rho_{\mathrm{S}}=0.85$ (VDI 3789 Blatt 2 1994).

Additionally, energy-efficient paint coatings show high transmittances in the visible spectrum but low transmittances at longer wavelengths (Hummel and Guenther 1995) resulting in an average coating transmittance of $\tau_{\mathrm{S} \text {, Coating }}=0.37$ in the interval from 350 to $2500 \mathrm{~nm}$. Then, $\rho_{\mathrm{S}, \text { Coated }}=1-\left(1-\rho_{\mathrm{S}}\right)$ $\tau_{\mathrm{S}, \text { Coating }}$ is the reflectance representing the reflective properties of the coated paint with regard to solar radiation.

The resultant long-wave radiation $R_{\mathrm{L}}$ is calculated as the difference between the incoming irradiance caused by the sky, the ground, ambient obstacles (buildings) or other components of the vehicle and the outgoing radiation. The latter depends on the corresponding surface temperature $\Theta_{\mathrm{S}}$ of the elements of the vehicle and is given by the Stefan-Boltzmann law as $R_{\mathrm{L}, \mathrm{S}}=\varepsilon_{\mathrm{L}} \sigma \Theta_{\mathrm{S}}{ }^{4}$ with long-wave total emissivity $\varepsilon_{\mathrm{L}}$ and Stefan-Boltzmann constant $\sigma=5.67 \times 10^{-8} \mathrm{~W} \mathrm{~m}^{-2} \mathrm{~K}^{-4}$.

For long-wave radiation, the vehicle's interior is treated as a black body. The situation is further simplified by neglecting view factors and only considering radiative exchange between parallel opposing surfaces, where the irradiance of the opposing surface is denoted as $R_{\mathrm{L} \text {,opp} \text {. }}$

In general, for receiving planes, the anisotropic distribution of the long-wave radiance of the sky dome and obstacles 
Table 1 Typical values of the coefficient of reflection $\rho_{\mathrm{S}}$, coefficient of reflection with coating applied $\rho_{\mathrm{S}, \text { Coated }}$ transmission $\tau_{\mathrm{S}}$ for short-wave (solar) radiation and the coefficient of absorption $\alpha_{\mathrm{L}}$ and emission $\varepsilon_{\mathrm{L}}$ for long-wave (thermal) radiation. Values of the latter two are assumed to be identical due to Kirchhoff's law

\begin{tabular}{llllll}
\hline Surface & Source & \multicolumn{2}{l}{ Short-wave solar radiation } & \multirow{2}{*}{ Long-wave thermal radiation } \\
\cline { 3 - 4 } & & $\rho_{\mathrm{S}}$ & $\rho_{\mathrm{S}, \text { Coated }}$ & $\tau_{\mathrm{S}}$ & $\alpha_{\mathrm{L}}=\varepsilon_{\mathrm{L}}$ \\
\hline White & Givoni (1998) & 0.7 & - & 0 & 0.90 \\
Metallic grey & Givoni (1998) & 0.77 & 0.92 & 0 & 0.90 \\
Orange & Smith et al. (2003) & 0.5 & - & 0 & 0.90 \\
Black & Givoni (1998) & 0.1 & 0.67 & 0 & 0.90 \\
Glass & Szczyrbowski et al. (1989) & - & 0.50 & 0.29 & 0.1 \\
Asphalt & Jansson et al. (2006) & 0.06 & - & - & 1.0 \\
Buildings & VDI 3789 Blatt 2 (1994) & 0.2 & - & - & 0.90 \\
\hline
\end{tabular}

above the geometric horizon (e.g. buildings and vegetation) has to be considered (VDI 3789 Blatt 2 1994). Therefore, the half space above a surface with the surface-normal orientation denoted in spherical coordinates as $(\alpha, \beta)$ was discretised in steps of $\Delta \alpha=\Delta \beta=5^{\circ}$. Each discretisation element was assigned a radiance $L_{i j}$ depending on whether it covered the sky, ground or other obstructions as indicated by $\gamma_{\mathrm{H}}$.

$$
L_{i j}(i, j)=\frac{1}{\pi} \sigma \begin{cases}\varepsilon_{\mathrm{Sky}}(\vartheta) \Theta_{A, o}^{4} & \text { sky at }(i \Delta \alpha, j \Delta \beta) \\ \varepsilon_{G n d} \Theta_{G \text { Gnd }}^{4} & \text { ground at }(i \Delta \alpha, j \Delta \beta) \\ \varepsilon_{B l d} \Theta_{A, o}^{4} & \text { obstruction at }(i \Delta \alpha, j \Delta \beta) \\ 0 & \text { for inner surfaces }\end{cases}
$$

Figure 3 shows a typical site with a building in the vicinity of the parked vehicles and the resulting radiance.

Summing over all discretisation elements within the half space and considering the angle of incident yields the total thermal radiation received by the plane. Therefore

$$
\begin{aligned}
R_{\mathrm{L}}= & \Delta \alpha \Delta \beta\left[\sum_{i=-18}^{17} \sum_{j=0}^{35} \sin \left(\beta_{j}\right) \cos \eta_{i j} L_{i j}(\Delta \alpha(0.5+i), \Delta \beta(0.5+j))\right] \\
& +R_{\mathrm{L}, \mathrm{opp}}-R_{\mathrm{L}, \mathrm{s}}
\end{aligned}
$$

with $\eta_{i j}$ as the angle between surface normal and discretisation element of the half space.

Heat is conducted through an opaque element according to $C=\lambda / d\left(\Theta_{\mathrm{S}, \mathrm{o}}-\Theta_{\mathrm{S}, \mathrm{i}}\right)$ with the heat conductivity $\lambda$, the thickness $d$ and the temperature of outer and inner surface of the element $\Theta_{\mathrm{S}, \mathrm{o}}$ and $\Theta_{\mathrm{S}, \mathrm{i}}$, respectively.

The heat transfer between two layers of different materials and surface temperatures $\Theta_{\mathrm{S}, 1}$ and $\Theta_{\mathrm{S}, 2}$, respectively, is given by $C=\alpha_{C}\left(\Theta_{\mathrm{S}, 1}-\Theta_{\mathrm{S}, 2}\right)$. To estimate the thermal contact conductance $\alpha_{C}$ at their interface across an area $A_{\mathrm{I}}$, a relation that takes into account the area of direct contact $A_{\mathrm{C}}$, the average spacing between the two layers $d_{\mathrm{C}}$ and the heat conductivity of air enclosed within the contact zone $\lambda_{\mathrm{A}}$ is applied:

$\alpha_{\mathrm{C}}=\frac{1}{d_{\mathrm{C}}}\left(\frac{A_{\mathrm{C}}}{A_{\mathrm{I}}} \frac{\lambda_{1} \lambda_{2}}{\lambda_{1}+\lambda_{2}}+\left(1-\frac{A_{\mathrm{C}}}{A_{\mathrm{I}}}\right) \lambda_{\mathrm{C}}\right)$
Choosing $A_{\mathrm{C}}=0.5 A_{\mathrm{I}}, d_{\mathrm{C}}=0.1 \mathrm{~mm}$ and the heat conductivity values for a contact zone between iron and insulating material as given in Table 2 results in $\alpha_{\mathrm{C}}=405 \mathrm{~W} / \mathrm{Km}^{2}$.

The vehicle is approximated as a hollow cuboid, and the opaque and transparent elements comprising its body are viewed as one-dimensional plane walls with heat being conducted only perpendicular to their surfaces. For a Mercedes Vito, the dimensions of the cuboid were chosen as $2.4 \times 1.9 \times 1.3 \mathrm{~m}^{3}$ and for the Mazda 616, $1.2 \times 1.6 \times 1.9 \mathrm{~m}^{3}$.

A lumped capacitance method with a discretisation length of $\Delta x=1 \mathrm{~mm}$ and a time step interval of $\Delta t=1 \mathrm{~s}$ is employed to describe the dynamic behaviour of the system. Each lump's change rate of internal energy is given by

$$
\begin{aligned}
c m \frac{d \Theta_{L}}{d t}= & A\left(\alpha_{\mathrm{L}} R_{\mathrm{L}}+\left(1-\rho_{\mathrm{S}}-\tau_{\mathrm{S}}\right) R_{\mathrm{S}}+K+C\right) \\
& +A_{\mathrm{p}}\left(1-\rho_{\mathrm{S}}\right) R_{\mathrm{S}, \tau}
\end{aligned}
$$

where $A$ is the surface area of the plane wall, $A_{\mathrm{p}}$ is the area irradiated by solar radiation transmitted to the interior $R_{\mathrm{S}, \tau}$, yielding its internal energy $U_{\mathrm{L}}$ at $t+\Delta t$ :

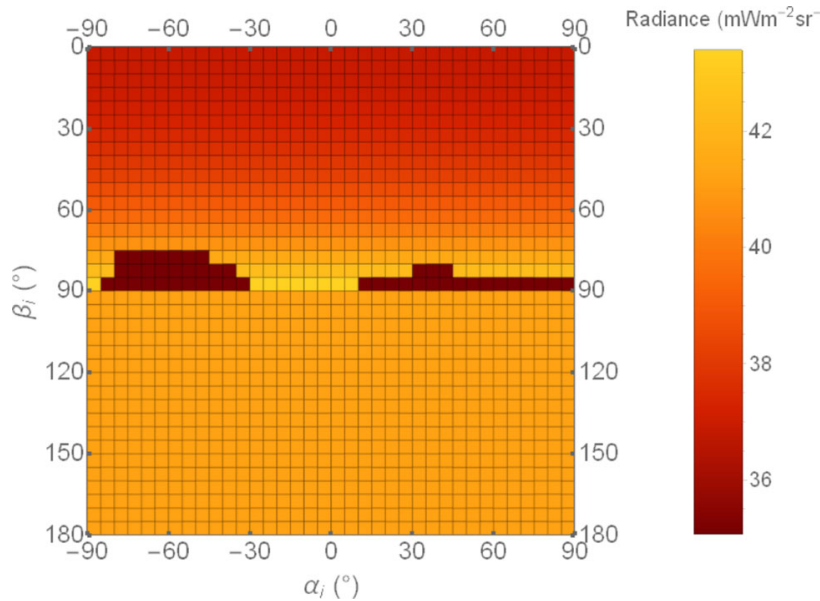

Fig. 3 Plot of the discretised half space above an outer surface oriented perpendicular to the ground. The radiances shown are not adjusted for the angle of incidence; the dark portions represent buildings in the vicinity of the vehicle. Thermal radiation from the sky at $\beta_{i}<90$ decreases noticeably with decreasing $\beta_{i}$ 
Table 2 Thermophysical properties of the materials of the simulated vehicles (Haynes 2015)

\begin{tabular}{lcccc}
\hline Parameter & Steel sheet & Glass & Air & Insulation \\
\hline Specific heat capacity $c\left(\mathrm{Jkg}^{-1} \mathrm{~K}^{-1}\right)$ & 449 & 450 & 1007 & 1300 \\
Heat conductivity $\lambda\left(\mathrm{WK}^{-1} \mathrm{~m}^{-1}\right)$ & 80 & 0.95 & 0.026 & 0.055 \\
Density $\rho\left(\mathrm{kgm}^{-3}\right)$ & 7870 & 2500 & 1.16 & 270 \\
\hline
\end{tabular}

$U_{\mathrm{L}}(t+\Delta \mathrm{t})=U_{\mathrm{L}}(t)+c m \frac{d \Theta_{\mathrm{L}}(t)}{d t} \Delta \mathrm{t}$

The output of the presented dynamical model therefore consists not only of the cabin air temperature but also of the cabin surface temperatures, which are relevant for calculating the mean radiation temperature.

A collection of the thermophysical properties of materials used in the simulations is shown in Table 2.

Windows were modelled as transparent elements of uniform temperature distribution and a thickness of $5 \mathrm{~mm}$. The outermost layer of opaque elements is approximated as a 1-mmthick iron sheet. While vehicle bodies are usually comprised of advanced high-strength steel sheets (Liu et al. 2010), their thermophysical properties can be approximated with those of iron. At the front and roof of every vehicle, a 5 -cm-thick layer of thermally insulating material is in thermal contact with the metal sheet, with the insulating layer's thickness at the remaining walls varying from vehicle to vehicle. For vehicles with a cargo hold, structurally separated from the driver cabin, the front side of the model cuboid was simulated without transparent elements. All lumps were initialised with a corresponding measured average temperature at $t=0$. An overview of the vehicle parameters chosen for simulations is given in Table 3 .

The model calculation takes about 3 min per simulated hour on a 3.8-GHz AMD FX-6300 processor. Multiprocessor capability was not implemented.

\subsection{Meteorological data}

The model is driven by the three meteorological parameters: ambient air temperature ( $2 \mathrm{~m}$ height) $\Theta_{\mathrm{A}, \mathrm{o}}$, the wind speed $v_{10}$ at a height of $z_{10}=10 \mathrm{~m}$ and the global radiation $G_{\mathrm{h}}$ on a horizontal receiving surface from standard meteorological stations. The maximum distance between the site of the vehicle measurements and meteorological station was less than $6 \mathrm{~km}$. All parameters were available at a temporal resolution of $1 \mathrm{~min}$ or $1 \mathrm{~h}$.

The short-wave radiation $R_{\mathrm{S}}$ on an inclined receiving surface is calculated from the global radiation $G_{\mathrm{h}}$ incident on a horizontal receiving surface taking into account the geometry of the Sun-Earth system and the geometry of the inclined surface (Schauberger 1992; WMO 2008). At some stations, the diffuse sky radiation $H_{\mathrm{h}}$ is also available; therefore, the direct solar radiation $D_{\mathrm{h}}$ on a horizontal receiving plane is given by $D_{\mathrm{h}}=G_{\mathrm{h}}-H_{\mathrm{h}}$. Otherwise, the former can be assessed by
$H_{\mathrm{h}}=G_{\mathrm{h}} \quad\left(1.400-1.749 k_{t}+0.177 \sin \gamma\right)$ (Reindl et al. 1990) for $0.3<k_{t}<0.78$ with the clearness index $k_{t}=G_{\mathrm{h}} /$ $S_{\mathrm{h}}$. Here, $S_{\mathrm{h}}$ represents the extraterrestrial solar irradiance on a horizontal receiving surface, calculated by $S_{\mathrm{h}}=S \sin \gamma$ with the solar constant $S=1366 \mathrm{~W} / \mathrm{m}^{2}$ and the solar elevation angle $\gamma$.

Incoming short-wave radiation from the upper-half sphere $R_{\mathrm{S} \text {,sky }}$ is given by the sum of the direct radiation $D$ and the diffuse radiation from the sky dome $H_{\mathrm{h}}$ by $R_{\mathrm{S}, \text { sky }}=D+H_{\mathrm{h}}$. Here, $D=\cos \eta D_{\mathrm{h}}$ where $\eta$ is the angle of incidence. The short-wave radiation from the lower-half sphere $R_{\mathrm{S}, \text { Gnd }}$ depends on the reflection of the global radiation on ambient surfaces (e.g. ground and buildings) and the short-wave radiation albedo, $r_{\mathrm{S}}$. The resulting short-wave radiation on an inclined receiving surface $R_{\mathrm{S}}$ is then given by the sum of the two half spheres $R_{\mathrm{S}}=R_{\mathrm{S}, \mathrm{sky}}+R_{\mathrm{S}, \mathrm{Gnd}}$.

Long-wave radiation from the upper-half sphere (sky) $R_{\mathrm{L}, \mathrm{Sky}}$ can be parameterised with the Stefan-Boltzmann law using the air temperature at $2 \mathrm{~m}$ height $\Theta_{\mathrm{A}, \mathrm{o}}(\mathrm{WMO} 2008)$. The emissivity is given as a function of the zenith angle $\varepsilon_{\text {Sky }}(\vartheta)=1-0.5 \exp$ $\left(-0.3(\kappa / \cos \vartheta)^{1 / 2}\right)$ with a dimensionless factor $\kappa$ depending on $\theta_{\text {A.o. }}$. For the temperature range between $268 \mathrm{~K} \leq \theta_{\text {A.o }} \leq 296 \mathrm{~K}$, it is defined by $\kappa=\exp \left[\left(\theta_{\text {A.o }}-257.6\right) / 15.47\right]$; while its tabulated values between 297 and 313 K (VDI 3789 Blatt 2 1994) can be approximated by a third order polynom $\sum_{i=0}^{3} a_{i} T^{i}$ where $a_{0}=-291,606, a_{1}=2916, a_{2}=-9.72$ and $a_{3}=0.011$ with relative errors below $3 \%$.

The surface temperature of the ground $\Theta_{\text {Gnd }}$ was calculated by the taking into account global radiation $G_{\mathrm{h}}$, convective heat flow depending on the air temperature $\Theta_{\mathrm{A}, \mathrm{o}}$ and wind velocity $v_{\mathrm{w}}$ and the heat flow due to conduction between the upper layer and a depth of $20 \mathrm{~cm}$, using the parameters of the ground from Jansson et al. (2006). For 06:00 in the morning, a uniform initial temperature equal to the air temperature at that time is assumed down to a depth of $20 \mathrm{~cm}$. The temperature below $20 \mathrm{~cm}$ is kept constant at the diurnal mean temperature of the previous day.

To calculate the wind velocity $v_{\mathrm{w}}$ at a vehicle height of $z=1 \mathrm{~m}$, a logarithmic wind profile $v_{\mathrm{w}}=v_{10} \ln \left(z / z_{0}\right) / \ln \left(z_{10} / z_{0}\right)$ was employed with surface roughness $z_{0}=1.5 \mathrm{~m}$ (Manwell et al. 2009).

\subsection{Vehicle measurements and model validation}

The dynamic model was validated with measurements during summer conditions for a delivery van represented by various Mercedes Vitos and a limousine using a Mazda 616. The 
Table 3 Characteristic parameters of the measured vehicles. The thickness of the thermally insulating layer at the side walls, floor and back wall is given by $d_{\text {Ins }}$, while the ratio of area covered by windows $A_{\mathrm{w}}$ to the total surface area of a wall $A$ is denoted by $A_{\text {rel }}$. Colour determines the optical properties of the cuboid's outer surfaces and interior colour those of its inner surfaces as listed in Table 1. All vehicles were Mercedes Vitos, except for O-2-1, which was a Mazda 616. The vehicle code gives an overview of the configuration, with the first letter indicating colour, the first number the thickness of the insulating layer, and the second number whether or not windows were installed $(0=$ no; $1=$ yes $)$

\begin{tabular}{|c|c|c|c|c|c|}
\hline \multirow{2}{*}{$\begin{array}{l}\text { Vehicle } \\
\text { code }\end{array}$} & \multirow[t]{2}{*}{ Colour } & \multirow{2}{*}{$\begin{array}{l}\text { Interior } \\
\text { colour }\end{array}$} & \multirow[t]{2}{*}{$d_{\text {Ins }}(\mathrm{cm})$} & \multicolumn{2}{|l|}{$A_{\text {rel }}(1)$} \\
\hline & & & & $\begin{array}{l}\text { Front/ } \\
\text { back }\end{array}$ & Sides \\
\hline B-2-1 & Black & Black & 2 & 0.4 & 0.3 \\
\hline $\mathrm{O}-2-1$ & Orange & Black & 2 & 0.3 & 0.3 \\
\hline G-2-1 & Metallic grey & Black & 2 & 0.4 & 0.3 \\
\hline W-2-1 & White & Black & 2 & 0.4 & 0.3 \\
\hline W-1-0 & White & - & 1 & 0 & 0 \\
\hline W-2-0 & White & - & 2 & 0 & 0 \\
\hline W-5-0 & White & - & 5 & 0 & 0 \\
\hline
\end{tabular}

typical parameters of these vehicles are summarised in Table 3. The cabin air temperature was measured with three sensors close to the roof, three sensors in the middle of the cabin and three sensors close to the floor (Testo174 data loggers from Testo $\mathrm{GmbH}$ with a measuring range of -30 to $70{ }^{\circ} \mathrm{C}$ ).

Besides the mean temperature $\Theta_{\text {Air }}$, as a mean over all nine measuring points, we calculated the floor temperature and the roof temperature to describe the inhomogeneity of the temperature distribution.

The model calculations were compared to several on-site measurements. The deviations from the model were described by the root mean squared error RMSE:

$\operatorname{RMSE}=\sqrt{\sum_{t=0}^{t_{\max }}\left(\Theta_{\text {Air }}(t)-\Theta_{\text {Air }}(t)\right)^{2}}$

and the absolute maximum error AME:

$\operatorname{AME}=\max \left|\Theta_{\text {Air }}(t)-\Theta_{\text {Air }}(t)\right|$,

and used as an indicator of model skill.

\section{Results}

\subsection{Comparison of model calculations with measurements}

The results of the simulation model were compared to measurements of the cabin air temperature for eight model runs. Figure 4 shows the time course of the measurements of the mean temperature and the temperature at roof and floor levels as well as the model calculation. The first four plots (Fig. 4a-d) are calculated for vehicles of various colours with windows but equal insulation thickness of $d_{\text {Ins }}=2 \mathrm{~cm}$, while Fig. $4 \mathrm{e}-\mathrm{h}$ shows simulations for white vehicles without windows and different values of insulation $d_{\text {Ins }}$.

For each model run, the model skill is expressed by RMSE and AME, with the highest observed RMSE in the case of W-1-0 (Fig. 4e). In this run, the modelled air temperature approximates the measured air temperature at roof level, which can be seen as an upper limit of the air temperature inside the cabin. However, photographs taken during the on-site measurement of the cabin air temperature indicate overcast skies at the measurement site. This is not reflected by the global radiation input data from the nearest meteorological station, leading to an overestimation of the cabin air temperature. An underestimation of the floor temperature by the model was not observed.

\subsection{Dynamic behaviour of the vehicles}

A direct comparison of the thermal performances of vehicles (defined in Table 1 and Table 3) was performed by setting the meteorological parameters to $G_{\mathrm{h}}=800 \mathrm{~W} / \mathrm{m}^{2}, H_{\mathrm{h}}=364 \mathrm{~W} /$ $\mathrm{m}^{2}, \Theta_{\mathrm{A}, \mathrm{o}}=40^{\circ} \mathrm{C}, \Theta_{\mathrm{Gnd}}=40{ }^{\circ} \mathrm{C}, v_{10}=0 \mathrm{~m} / \mathrm{s}, \gamma=62.5^{\circ}$ and $\psi=180^{\circ}$. To evaluate the influence of windows, an additional windowless vehicle configuration W-2-0 on the basis of W-21 was added.

The calculated time course of the cabin air temperature $\Theta_{\text {Air }}$ was then fitted with an exponential function $\Theta=\Theta_{0}+$ $\Theta_{D}[1-\exp (-k t)]$ with fit parameters $\Theta_{\mathrm{D}}$ and $k$. The time $t \rightarrow \infty$ yields the equilibrium temperature $\Theta_{\mathrm{E}}=\Theta_{0}+\Theta_{\mathrm{D}}$ of the simulated scenario. Maximum heating rates $P(\mathrm{~W})$ were extracted directly from the model calculations. These parameters are summarised in Tables 4 and 5. The equilibrium temperature $\Theta_{\mathrm{E}}$ describes the thermal steady state of the cabin, whereas the other parameters depend strongly on the dynamic process of the cabin heating.

Windows have a major influence on the reached equilibrium temperature $\Theta_{\mathrm{E}}$, allowing solar radiation to be transmitted to the vehicle's interior (Fig. 5a, vehicle configurations $\mathrm{X}-\mathrm{x}-0$ compared to $\mathrm{X}-\mathrm{X}-1)$. This in turn leads to increased temperature of interior surfaces and therefore a higher contribution towards the heating of the cabin air. Only configuration G-21 shows a lower equilibrium temperature $\Theta_{\mathrm{E}}$ than all windowless configurations due to the high reflectivity of its outer surfaces, reflecting a large portion of inciding solar radiation and thereby compensating the solar radiation transmitted to its interior. The maximum of the time course of the heating rate $P$ is dependent on the insulation (Fig. 5b). For a thickness of only $d_{\text {Ins }}=1 \mathrm{~cm}$, the maximum is reached in about $10 \mathrm{~min}$, for $d_{\text {Ins }}=2 \mathrm{~cm}$ in about $20 \min$ and for $d_{\text {Ins }}=5 \mathrm{~cm}$, the maximum is reached after $1 \mathrm{~h}$. This has a strong influence on the slope of the temperature change of the cabin air 


$$
-\bar{\Theta}_{\text {Air }} \text { calculated } \odot \bar{\Theta}_{\text {Air }}-\bar{\Theta}_{\text {Air,Floor }} \bar{\Theta}_{\text {Air,Roof }}
$$

(a) $B-2-1$

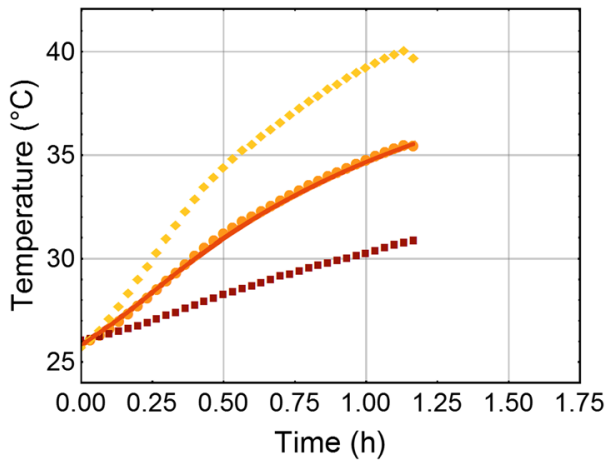

(c) G-2-1

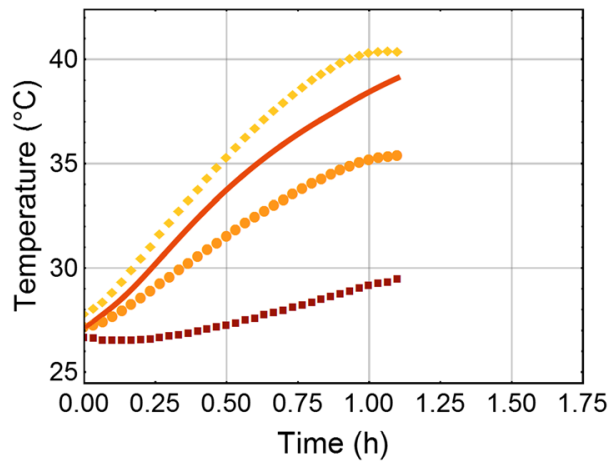

(e) $W-1-0$

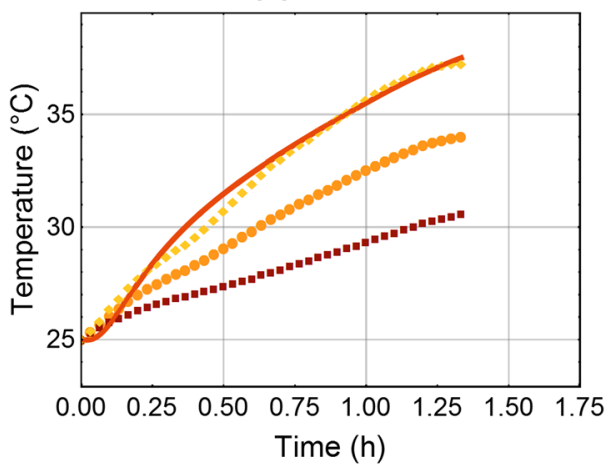

(g) $W-5-0$

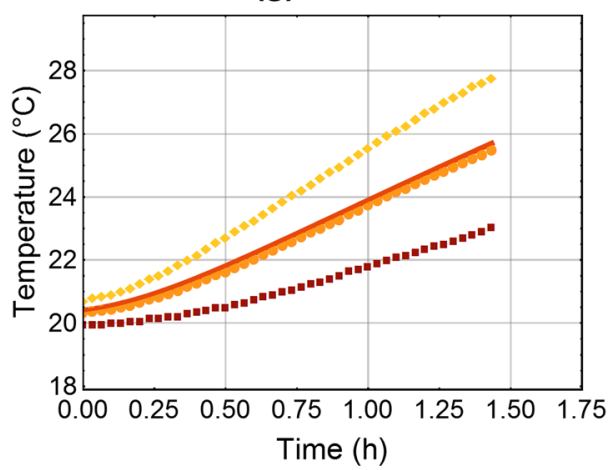

19.08.2008

10:35-12:01

$\bar{G}=720 \pm 73 \mathrm{~W} / \mathrm{m}^{2}$

$\bar{\theta}_{A, 0}=24 \pm 1.4^{\circ} \mathrm{C}$

$\bar{v}_{10}=1 \pm 0.8 \mathrm{~m} / \mathrm{s}$

RMSE $=0.2 \mathrm{~K}$

$\mathrm{AME}=0.2 \mathrm{~K}$

Fig. 4 Time course of the modelled cabin air temperature (red line), the measured mean air temperature and the temperature at floor and roof level inside the cabin. The code above each plot refers to the simulated vehicle configuration (Table 3). For each model run, the date of measurement, (b) $0-2-1$

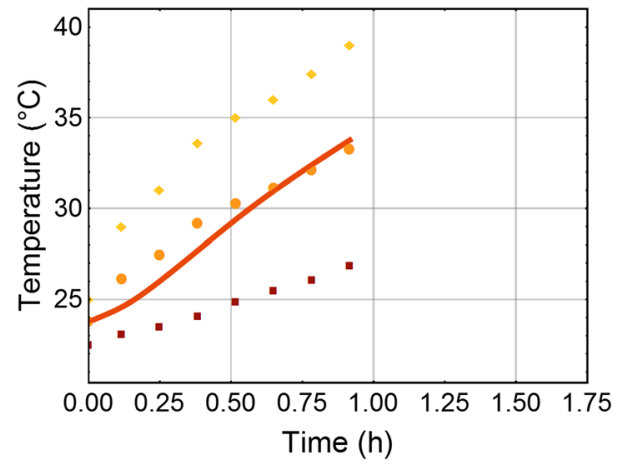

05.08 .1981

08:30-09:26

$\bar{G}=440 \pm 49 \mathrm{~W} / \mathrm{m}^{2}$

$\bar{\theta}_{A, o}=23 \pm 0.4^{\circ} \mathrm{C}$

$\bar{v}_{10}=0 \pm 0 . \mathrm{m} / \mathrm{s}$

RMSE $=1 . \mathrm{K}$

$\mathrm{AME}=1.6 \mathrm{~K}$

(d) $\mathrm{W}-2-1$

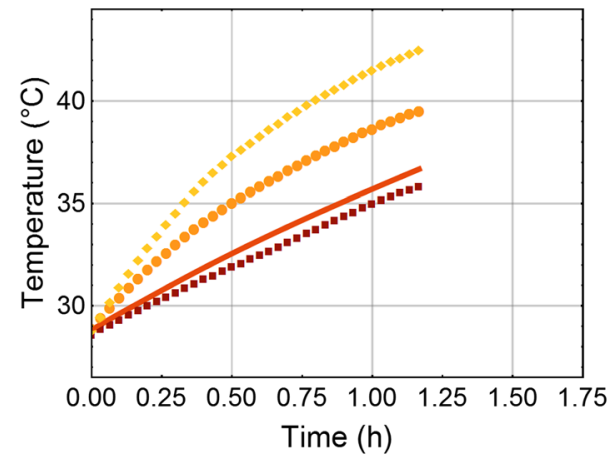

06.09 .2008

10:53-12:03

$\bar{G}=561 \pm 134 \mathrm{~W} / \mathrm{m}^{2}$

$\bar{\theta}_{A, 0}=26 \pm 2.4^{\circ} \mathrm{C}$

$\bar{v}_{10}=1 \pm 0.2 \mathrm{~m} / \mathrm{s}$

RMSE $=2.3 \mathrm{~K}$

$\mathrm{AME}=2.9 \mathrm{~K}$

(f) $W-5-0$

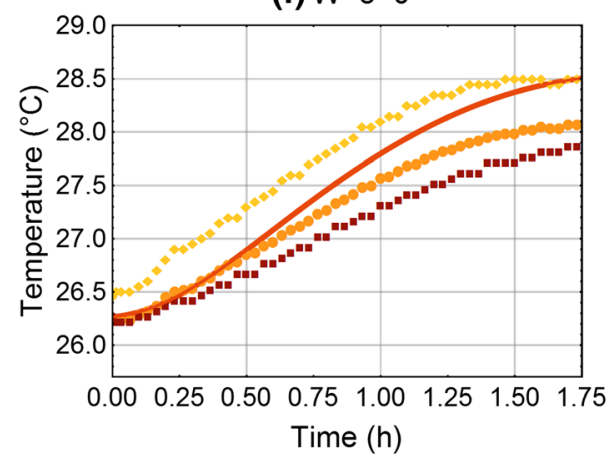

06.08 .2008 16:20-18:12 $\bar{G}=202 \pm 160 \mathrm{~W} / \mathrm{m}^{2}$ $\bar{\theta}_{A, 0}=26 \pm 1 .{ }^{\circ} \mathrm{C}$ $\bar{v}_{10}=2 \pm 0.5 \mathrm{~m} / \mathrm{s}$

RMSE $=0.3 \mathrm{~K}$

$\mathrm{AME}=0.5 \mathrm{~K}$

(h) $\mathrm{W}-5-0$

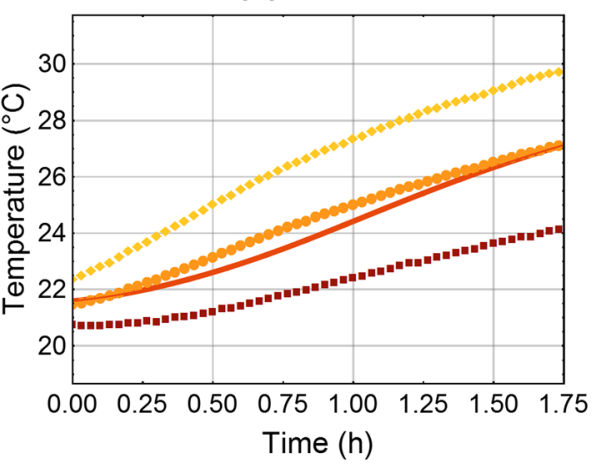

25.08 .2008

11:30-15:56

$\bar{G}=555 \pm 192 \mathrm{~W} / \mathrm{m}^{2}$

$\bar{\theta}_{A, 0}=22 \pm 1.4^{\circ} \mathrm{C}$

$\bar{v}_{10}=2 \pm 0.6 \mathrm{~m} / \mathrm{s}$

RMSE $=0.5 \mathrm{~K}$

$\mathrm{AME}=1.1 \mathrm{~K}$

duration of measurement, mean values and standard deviations of the meteorological input parameters $G, \Theta_{\mathrm{A}, \mathrm{o}}, v_{10}$, and the model skill parameters root mean squared error RMSE, and absolute maximum error AME, all evaluated for the entire duration, are given 
Table 4 Parameters describing the steady-state situation and the dynamic behaviour of the temperature rise of the cabin by the equilibrium temperature $\Theta_{\mathrm{E}}$, the time when $50 \%$ of the difference between ambient temperature and equilibrium temperature is reached $t_{50 \%}$, time of maximum heating rate $t_{\text {Max }}$ and maximum heating rate $P_{\max }$

\begin{tabular}{lllll}
\hline Vehicle & $\Theta_{\mathrm{E}}\left({ }^{\circ} \mathrm{C}\right)$ & $t_{50 \%}(\min )$ & $t_{\max }(\min )$ & $P_{\max }(\mathrm{W})$ \\
\hline G-2-1 & 51 & 19 & 19 & 36 \\
W-1-0 & 54 & 10 & 10 & 97 \\
W-2-0 & 55 & 23 & 20 & 50 \\
W-5-0 & 59 & 73 & 64 & 22 \\
B-2-1 & 61 & 29 & 19 & 49 \\
W-2-1 & 61 & 27 & 19 & 50 \\
O-2-1 & 69 & 31 & 18 & 38 \\
\hline
\end{tabular}

temperature. For the most common thickness of the insulation of about $d_{\text {Ins }}=2 \mathrm{~cm}$, we can expect that most of the temperature change will occur in the first hour.

\subsection{Sensitivity study}

To investigate the influence of the model input parameters, only one single parameter was changed by $25 \%$ of the initial value; the model result was compared to the initial setup (Table 5). The simulations were performed for the configuration of vehicle W-2-1 and constant meteorological parameters, as used before.

The change of the equilibrium temperature $\Delta \Theta_{\mathrm{E}}$ describes the influence of the change of the selected parameter on the thermal steady state of the cabin. Ambient temperature, wind velocity, global radiation and paint reflectivity show the strongest influence. The alteration of the dynamic behaviour is shown by variations in the maximum heating rate $\Delta P_{\max }$, which, additionally, is sensible to the thickness of the insulating layer $d_{\text {Ins }}$, and the initial temperature $\Theta_{0}$.

In forensic scenarios, the initial temperature $\Theta_{0}$ and the time at which a vehicle was parked with the HVAC system switched off $t_{0}$ may not be known with certainty. To investigate the model sensitivity with respect to these parameters, time courses of the cabin air temperature for different initial conditions were calculated and are plotted in Fig. 6a, b.

The uncertainty in the initial temperature of the cabin air $\Theta_{0}=21.5^{\circ} \mathrm{C}$ was assumed to be $\Delta \Theta_{0}= \pm 5^{\circ} \mathrm{C}$ and the uncertainty in $\Delta t_{0}= \pm 0.5 \mathrm{~h}$. Calculations were performed for vehicle configuration W-5-0 with meteorological input data from the model run shown in Fig. $4 \mathrm{~h}$. This vehicle configuration shows a slow transition from the initial temperature $\Theta_{0}$ to the equilibrium temperature $\Theta_{\mathrm{E}}$ due to its thick insulation and the lack of windows (see also Fig. 5). Therefore, this configuration is influenced strongest by the two parameters $\Theta_{0}$ and $t_{0}$. In cases of a faster transition caused, for instance, by thinner insulation or solar radiation being transmitted to interior due to windows, the influence of the uncertainty on the calculated cabin air temperature will be considerably smaller. The initial temperature $\Theta_{0}$ has a much stronger influence on the time course than the time shift. However, after $4 \mathrm{~h}$, all calculated temperatures lie within a $2{ }^{\circ} \mathrm{C}$ interval.

These results show that input parameters may be classified in three groups, depending on which quantities are influenced. They may either affect (1) the equilibrium temperature, (2) the heating rate or (3) both. If, for instance, the focus of model application is the calculation of the steady-state equilibrium temperature with high accuracy, then parameters of groups 1 and 3 have a major influence.

\section{Discussion}

As long as a vehicle is in operation, the cabin climate is conditioned by the ventilation and/or the AC system. In the case of a parked vehicle, it is entirely passive and exposed to the environment. The transition from the operational state to steady state, which is expressed by the equilibrium temperature, was described by a dynamic model. The model is driven by the three meteorological parameters: air temperature (at $2 \mathrm{~m}$ height), global solar radiation and wind velocity (at $10 \mathrm{~m}$ height). Additional investigation suggests that model performance is mostly independent from the temporal resolution of the meteorological input data. For data with a temporal resolution of $1 \mathrm{~min}$, the RMSE $=0.47 \mathrm{~K}$, for a resolution of $1 \mathrm{~h}$ RMSE $=0.48 \mathrm{~K}$ (Fig. 4h). This means that meteorological data on an hourly basis are sufficient, which are available at most of the meteorological stations. Due to the fact that air temperature and global radiation show, in general, a conservative behaviour in space (Schmalwieser and Schauberger 2001), only the wind velocity has to be evaluated taking into account the local situation (e.g. buildings, terrain). The limitation to only three meteorological parameters, according to availability at a standard meteorological station, is an important feature to improve the applicability of the model.

The dynamic behaviour of the model was evaluated by measurements of the transition of the cabin air temperature to equilibrium temperature by several vehicles. Their geometry was simplified as far as possible. The results presented in Fig. 5 and Table 4 show that the cabin air temperature reaches $50 \%$ of the equilibrium temperature in all but one case in about $30 \mathrm{~min}$. For the windowless vehicle with the thickest insulating layer, the duration is more than $1 \mathrm{~h}$. The results show that the majority of the heating process occurs during this period, which is the time range for children and pets left unattended in a vehicle to reach harm (Grundstein et al. 2015a; Grundstein et al. 2011). The dynamic behaviour of the temperature increase after parking a vehicle in the sun has also been described elsewhere (Gibbs et al. 1995; Gregory and Constantine 1996; Jascha and Keck 1984; King et al. 1981; 
Table 5 Variation of the equilibrium temperature $\Delta \Theta_{\mathrm{E}}$ and the maximum heating flow rate $\Delta P_{\max }$ due to a $25 \%$ change of only one model parameter compared to the initial setup. In the two cases, the parameter was changed by different values; the corresponding modifiers are listed in rectangular brackets

\begin{tabular}{|c|c|c|c|c|}
\hline \multirow[t]{2}{*}{ Parameter } & \multicolumn{2}{|c|}{$\Delta \Theta_{\mathrm{E}}(\mathrm{K})$} & \multicolumn{2}{|c|}{$\Delta P_{\max }(\mathrm{W})$} \\
\hline & $-25 \%$ & $+25 \%$ & $-25 \%$ & $+25 \%$ \\
\hline Ambient temperature $\Theta_{\mathrm{A}, \mathrm{o}}=40 \pm 10^{\circ} \mathrm{C}$ & -10 & 10 & -14 & 15 \\
\hline Wind speed $v_{10}=0[+5 ;+10] \mathrm{m} / \mathrm{s}$ & -5 & -8 & +4 & +2 \\
\hline Global radiation $G_{\mathrm{h}}=800 \pm 200 \mathrm{~W}$ & -4 & 4 & -4 & 4 \\
\hline Reflectivity of paint $\rho_{\mathrm{S} \text {,Paint }}=0.7 \pm 0.08$ & -3 & 3 & -4 & 4 \\
\hline Thickness of insulating layer $d_{\text {Ins }}=2 \pm 0.5 \mathrm{~cm}$ & -1 & 1 & 18 & -11 \\
\hline Transmittance glass $\tau_{\mathrm{S}, \text { Glass }}=0.29 \pm 0.07$ & -1 & 1 & -2 & 1 \\
\hline Heat conductivity insulator $\lambda_{\text {Iso }}=55 \pm 14 \mathrm{~mW} / \mathrm{Km}$ & 1 & -1 & -4 & 2 \\
\hline Thermal absorptivity of paint $\alpha_{\mathrm{L}, \text { Paint }}=0.9[+0.1 ;-0.225]$ & 3 & -1 & -1 & 0 \\
\hline Initial temperature $\Theta_{0}=21.5 \pm 5.4^{\circ} \mathrm{C}$ & 0 & 0 & 7 & -8 \\
\hline
\end{tabular}

McLaren et al. 2005; Roberts and Roberts 1976). The model results are supported by these studies. Dadour et al. (2011) and Levinson et al. (2011) used statistical regression models to describe the time course of the cabin air temperature, with the limitation that these models have to be fitted to measurement. This will reduce their applicability especially for forensic purposes, when no measurements are available. Our model, with the explicit description of all energy fluxes can be applied without further calibration.

The most effective measure to reduce the inside temperature is to increase the ventilation by partly opened windows (Jascha and Keck 1984; King et al. 1981; Roberts and Roberts 1976; Surpure 1982). The protection of the windows by various covers to reduce the incoming solar radiation was investigated for paper, fabrics and aluminium foil (Al-Kayiem et al. 2010; Jascha and Keck 1984) and solar reflective coatings (Devonshire and Sayer 2005; Jasni and Nasir 2012; Rugh et al. 2007; Rugh and Farrington 2008). These investigations found a reduction up to $11 \mathrm{~K}$ for the cabin air temperature and a higher rating of thermal comfort (Devonshire and Sayer 2005), compared to unprotected windows.

A sensitivity study and the deviation between measured and modelled data showed that colour is a crucial factor. In the automotive industry, specialised optical coatings are used (Hummel and Guenther 1995; Smith et al. 2003; Szczyrbowski et al. 1989) to reduce the heat load. Simulations for vehicles with uncoated paint show higher equilibrium temperatures and heating rates for vehicles with darker colours, ranging from $61{ }^{\circ} \mathrm{C}$ for white $(\mathrm{W}-2$ 1) to $80{ }^{\circ} \mathrm{C}$ for black (B-2-1). This is in agreement with measurements of Levinson et al. (2011). By applying solar reflecting films on the roof, Rugh and Farrington (2008) found a reduction of about $7 \mathrm{~K}$ which results in a reduction of $1 \mathrm{~K}$ for the cabin air temperature. In the sensitivity study, we changed the transmittance of the glass by \pm 0.07 , which results in a reduction of about $1 \mathrm{~K}$ of the cabin air temperature. Taking into account a reduction which can be achieved by window films (visible light transmission in the range of $24 \%$ in California), a reduction of the cabin air temperature of $5 \mathrm{~K}$ as reported by Jasni and Nasir (2012) is plausible.

To assess the thermal load of an organism (humans as well as animals), more complex models are needed due to metabolic heat production (Grundstein et al. 2010; Schuliar et al. 2001) of the body and the necessity to stabilise the core temperature in a narrow interval by modifying the heat release of the body (e.g. Cheng et al. 2012; Dixit and Gade 2015). For a steady-state situation, after achieving the equilibrium temperature, this was calculated by Schuliar et al. (2001) for two children that were left unattended in a vehicle.

Grundstein et al. (2015a) combined measured cabin air temperature with a Man-Environment Heat Exchange Model (MENEX) to calculate the time dependent core temperature of a 1-year-old child to determine the duration that is needed
Fig. 5 Time course of the modelled mean cabin air temperature $\Theta_{\text {Air }}$ (a) and the heating rate $P(\mathbf{b})$ for vehicles of different configurations, subject to constant meteorological conditions

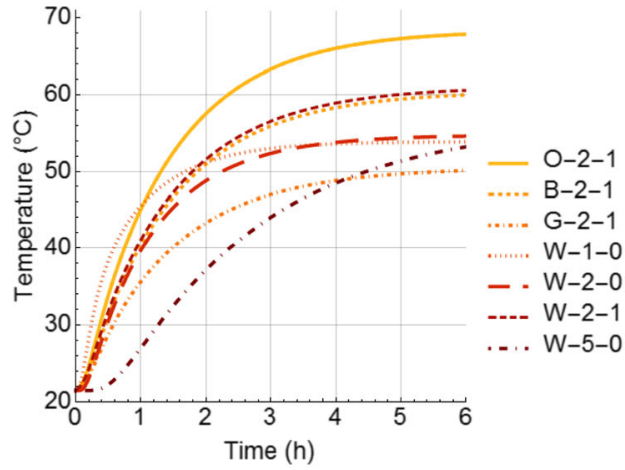

(a)

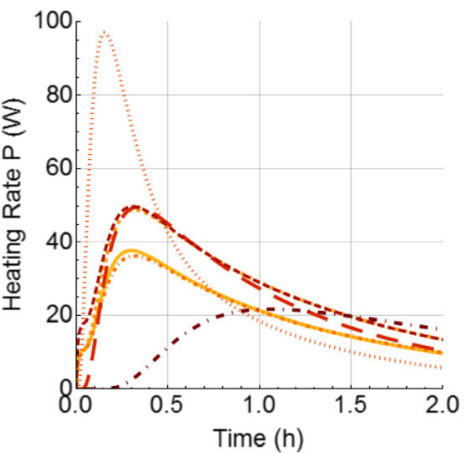

(b) 
Fig. 6 Time course of the calculated cabin air temperatures for variations in the initial conditions. In a, the initial temperature $\Theta_{0}$ was varied by $\pm 5^{\circ} \mathrm{C}$, while in $\mathbf{b}$, the start time $t_{0}$ was shifted by $\pm 0.5 \mathrm{~h}$. For comparison, the model calculation for the unchanged initial conditions is included in each plot

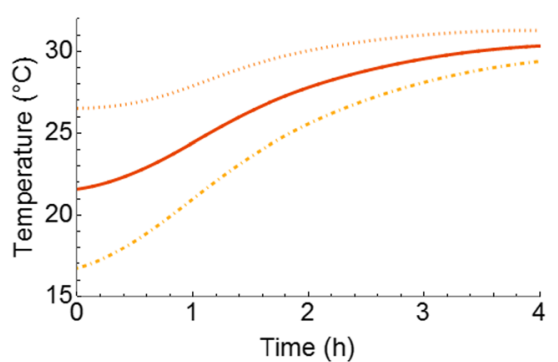

- $\Theta_{\text {Air }}$ initial conditions
$\ldots \Theta_{\text {Air }}$ for $\Delta \Theta_{0}=-5^{\circ} \mathrm{C}, \mathrm{RMSE}=2.9 \mathrm{~K}, \mathrm{AME}=4.8 \mathrm{~K}$
$\ldots \Theta_{\text {Air }}$ for $\Delta \Theta_{0}=+5{ }^{\circ} \mathrm{C}, \mathrm{RMSE}=2.4 \mathrm{~K}, \mathrm{AME}=5.0 \mathrm{~K}$

(a)

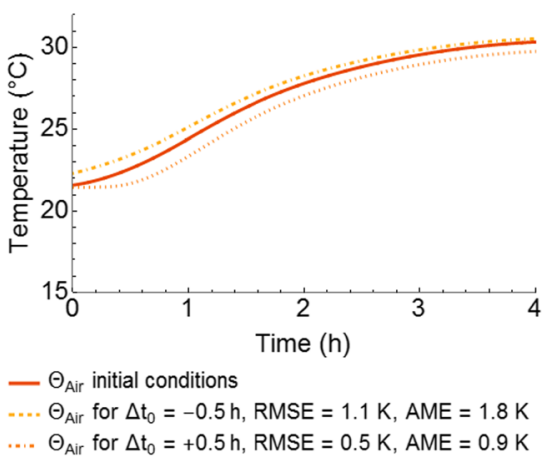

(b) to exceed the limit temperature for uncompensable heating $\left(>37^{\circ} \mathrm{C}\right)$ and hyperthermia $\left(>40{ }^{\circ} \mathrm{C}\right)$. The results show that these effects can be expected in less than $30 \mathrm{~min}$. The combination of our dynamic model to calculate the cabin air temperature with a model that describes the man-environment heat exchange would be an appropriate forensic tool to predict hyperthermia time course, as posed by Grundstein et al. (2015b).

Besides the cabin air temperature and the cabin surface temperature of the vehicles, as an output of our model, exposure of the body to direct solar radiation, which penetrates through the transparent parts of the vehicles, has to be taken into account to calculate the energy balance of the organism. The mean radiant temperature can then be assessed by models like RayMan (Matzarakis et al. 2007; Matzarakis et al. 2010) to calculate thermal indices that describe the thermal comfort (Rupp et al. 2015; Zhao et al. 2014) by, e.g. predicted mean vote (PMV), physiologically equivalent temperature (PET), standard effective temperature (SET*) and Universal Thermal Climate Index (UTCI).

In addition, temperature-sensitive goods like drugs (Haberleitner et al. 2014; Ondrak et al. 2015) and electronic devices can be adversely affected by high cabin temperature and exposure to solar radiation. Storage temperatures outside the recommended range can affect the quality of drugs (Gammon et al. 2008). Exceedance of the upper limit of the recommended temperature range may cause a loss of drug quality due to degradation processes. The inactivation process is described by the Arrhenius equation: the higher the temperature, the higher the degradation of active substances using the mean kinetic temperature (De Winter et al. 2013; Haynes 1971; ICH Q1A(R2) 2003; Nakamura et al. 2013). The mandatory shelf life of a temperature-sensitive drug allows for a degradation of active substances of less than $5 \%$ during correct storage (ICH Q1A(R2) 2003; ICH Q1E 2003; Küpper et al. 2006). For a typical drug, an increase in the mean kinetic temperature of $5{ }^{\circ} \mathrm{C}$ will decrease the drug's shelf life by a factor of two (Allegra et al. 1999). For the USA, the storage standards of the US Pharmacopeial Convention are summarised by Brown and Campagna (2005).

\section{Conclusions}

The thermal climate inside parked vehicles can be a live threatening environment for unattended children and pets. Each year about 37 children in the USA suffer a lethal heat stroke inside parked vehicles. In addition, thermal sensitive goods like drugs in ambulances and vehicles for veterinarians can be affected. To assess the thermal situation during parking of a vehicle, a dynamic model was developed. This model calculates the transition of the thermal conditions in the interior of a vehicle with its engine turned off from its initial state (e.g. immediately after having been in operation with active HVAC) to the steady state in the equilibrium situation. The model is driven only by three standard meteorological parameters: (1) the air temperature, (2) the wind velocity and (3) the global radiation, which is an advantage for its applicability. The transitional period lasts for about $60 \mathrm{~min}$, which means that even a short exposure time of less than $60 \mathrm{~min}$ can be live threatening by causing a heat stroke. To assess the thermal load of an organism (humans as well as animals), more complex models are needed to include metabolic heat production and the heat release of the body. This would benefit forensic applications with the aim to calculate the point of time when uncompensable heating $\left(>37^{\circ} \mathrm{C}\right)$ and/or hyperthermia $\left(>40^{\circ} \mathrm{C}\right)$ occurs.

Acknowledgments Open access funding provided by University of Veterinary Medicine Vienna. The study was partly funded by the Austrian Federal Ministry of Health, Family and Youth (BMGFJ-70420/0303-I/A/15/ 2007) and the Austrian Federal Chamber of Veterinarians. We thank the Austrian Weather Service (Central Institute for Meteorology and Geodynamics) for providing the meteorological data. This study was also supported by the Provincial Government of Lower Austria, Animal Health Service, Kärnten, Austria, Richter Pharma AG, Wels, Austria, Bayer Austria Ges.m.b.H., Wien, Austria, IntervetGes.m.b.H. Vienna, Austria, Testo GmbH, Vienna, Austria, Indulab AG, Gams, Schweiz, and Kramer Autoapotheken, Augsburg, Germany. The vehicles for the measurements were provided by Richter Pharma AG and the Georg Pappas Automobil AG. We are grateful to Astrid Haberleitner, who supported the measurements.

\section{Compliance with ethical standards}

Conflict of interest The authors declare that they have no competing interests. 
Open Access This article is distributed under the terms of the Creative Commons Attribution 4.0 International License (http:// creativecommons.org/licenses/by/4.0/), which permits unrestricted use, distribution, and reproduction in any medium, provided you give appropriate credit to the original author(s) and the source, provide a link to the Creative Commons license, and indicate if changes were made.

\section{References}

Al-Kayiem HH, Sidik MFBM, Munusammy YRAL (2010) Study on the thermal accumulation and distribution inside a parked car cabin. Am J Appl Sci 7:784-789

Alahmer A, Mayyas A, Mayyas AA, Omar MA, Shan D (2011) Vehicular thermal comfort models; a comprehensive review. Appl Therm Eng 31:995-1002. doi:10.1016/j.applthermaleng.2010.12.004

Allegra JR, Brennan J, Lanier V, Lavery R, MacKenzie B (1999) Storage temperatures of out-of-hospital medications. Acad Emerg Med 6: 1098-1103

Booth JN, Davis GG, Waterbor J, McGwin G Jr (2010) Hyperthermia deaths among children in parked vehicles: an analysis of 231 fatalities in the United States, 1999-2007. Forensic Sci Med Pathol 6:99-105

Böttcher C, Konz M (2011) The influence of heating and air conditioning systems on the cruising range of electric cars. In: 20. Aachener Kolloquium, Aachen, 10-20 October 2011. fwa Forschungsgesellschaft Kraftfahrwesen Aachen.

Brown LH, Campagna JD (2005) Medication storage in the EMS environment: understanding the science and meeting the standards. Emerg Med Serv 34:71 73-77, 90

Bruchim Y, Loeb E, Saragusty J, Aroch I (2009) Pathological findings in dogs with fatal heatstroke. J Comp Pathol 140:97-104

Cheng Y, Niu J, Gao N (2012) Thermal comfort models: a review and numerical investigation. Build Environ 47:13-22. doi:10.1016/j. buildenv.2011.05.011

Dadour IR, Almanjahie I, Fowkes ND, Keady G, Vijayan K (2011) Temperature variations in a parked vehicle. Forensic Sci Int 207:205211. doi:10.1016/j.forsciint.2010.10.009

De Winter S, Vanbrabant P, Vi NTT, Deng X, Spriet I, Van Schepdael A, Gillet JB (2013) Impact of temperature exposure on stability of drugs in a real-world out-of-hospital setting. Ann Emerg Med 62:380 387.e381. doi:10.1016/j.annemergmed.2013.04.018

Devonshire JM, Sayer Jr (2005) Radiant heat and thermal comfort in vehicles. Hum Factors 47:827-839

DIN 1946-3 (2006) Raumlufttechnik - Teil 3: Klimatisierung von Personenkraftwagen und Lastkraftwagen (Ventilation systems Part 3: Airconditioning of passenger cars and commercial vehicles). Beuth Verlag, Berlin

Dixit A, Gade U (2015) A case study on human bio-heat transfer and thermal comfort within CFD. Build Environ 94:122-130. doi:10.1016/j. buildenv.2015.07.016

Fruin SA, Hudda N, Sioutas C, Delfino RJ (2011) Predictive model for vehicle air exchange rates based on a large, representative sample. Environ Sci Technol 45:3569-3575. doi:10.1021/es103897u

Gammon DL, Su S, Huckfeldt R, Jordan J, Patterson R, Finley PJ, Lowe C (2008) Alteration in prehospital drug concentration after thermal exposure. Am J Emerg Med 26:566-573. doi:10.1016/j.ajem.2007.09.004

Gibbs LI, Lawrence DW, Kohn MA (1995) Heat exposure in an enclosed automobile. J La State Med Soc Off Organ La State Med Soc 147: $545-546$

Givoni B (1998) Climate considerations in building and urban design. Wiley, New York

Gregory NG, Constantine E (1996) Hyperthermia in dogs left in cars. Vet Rec 139:349-350
Grundstein A, Dowd J, Meentemeyer V (2010) Quantifying the heatrelated hazard for children in motor vehicles. Bull Am Meteorol Soc 91:1183-1191

Grundstein A, Duzinski S, Null J (2015a) Impact of dangerous microclimate conditions within an enclosed vehicle on pediatric thermoregulation. Theor Appl Climatol. doi:10.1007/s00704-015-1636-2

Grundstein A, Meentemeyer V, Dowd J (2009) Maximum vehicle cabin temperatures under different meteorological conditions. Int $\mathrm{J}$ Biometeorol. doi:10.1007/s00484-009-0211-x

Grundstein A, Null J, Meentemeyer V (2011) Weather, geography, and vehicle-related hyperthermia in children. Geogr Rev 101:353-370. doi:10.1111/j.1931-0846.2011.00101.x

Grundstein AJ, Duzinski SV, Dolinak D, Null J, Iyer SS (2015b) Evaluating infant core temperature response in a hot car using a heat balance model forensic. Sci Med Pathol 11:13-19. doi:10.1007/s12024-014-9619-7

Guard A, Gallagher SS (2005) Heat related deaths to young children in parked cars: an analysis of 171 fatalities in the United States, 19952002. Inj Prev 11:33-37. doi:10.1136/ip.2003.004044

Haberleitner A, Schauberger G, Horak J, Schmerold I (2014) Thermal drug storage conditions in veterinary vehicles - a one-year field study in Austria. Wien Tierärztl Monatsschr 101:110-119

Haynes JD (1971) Worldwide virtual temperatures for product stability testing. J Pharm Sci 60:927-929

Haynes WM (2015) CRC handbook of chemistry and physics, 96th edn. CRC Press, Canada

Hummel RE, Guenther KH (Eds) (1995) Handbook of optical properties: thin films for optical coatings vol 1. CRC Press, Boca Raton

ICH Q1A(R2) (2003) Stability testing of new drug substances and products Q1A(R2) Step 4. International Conference on Harmonisation of Technical Requirements for Registration of Pharmaceuticals for Human Use, Geneva

ICH Q1E (2003) Evaluation for Stability Data Q1E. International Conference on Harmonisation of Technical Requirements for Registration of Pharmaceuticals for Human Use, Geneva

Jansson C, Almkvist E, Jansson PE (2006) Heat balance of an asphalt surface: observations and physically-based simulations. Meteorol Appl 13:203-212. doi:10.1017/S1350482706002179

Jascha I, Keck G (1984) Klima im Personenkraftwagen - ein Beitrag zum Tierschutz. Wien Tierärztl Monatschr 71:227-237

Jasni MA, Nasir FM (2012) Experimental comparison study of the passive methods in reducing car cabin interior temperature. In: International Conference on Mechanical, Automobile and Robotics Engineering (ICMAR'2012). Penang, Malaysia, 2012. pp 229-233

Kaynakli O, Pulat E, Kilic M (2005) Thermal comfort during heating and cooling periods in an automobile. Heat Mass Transf/ WärmeStoffübertragung 41:449-458. doi:10.1007/s00231-004-0558-9

King K, Negus K, Vance JC (1981) Heat stress in motor vehicles: a problem in infancy. Pediatrics 68:579-582

Küpper TEAH, Schraut B, Rieke B, Hemmerling AV, Schöffl V, Steffgen J (2006) Drugs and drug administration in extreme environments. J Travel Med 13:35-47. doi:10.1111/j.1708-8305.2006.00007.x

Levinson R, Pan H, Ban-Weiss G, Rosado P, Paolini R, Akbari H (2011) Potential benefits of solar reflective car shells: cooler cabins, fuel savings and emission reductions. Appl Energy 88:4343-4357. doi:10.1016/j. apenergy.2011.05.006

Liu HS, Xing ZW, Bao J, Song BY (2010) Investigation of the hot-stamping process for advanced high-strength steel sheet by numerical simulation. J Mater Eng Perform 19:325-334. doi:10.1007/s11665-009-9510-y

Liu J, Zeng S (2012) Progresses and needs in cabin environment research of transport vehicles. Build Environ 47:3-4. doi:10.1016/j. buildenv.2011.08.003

Manwell JF, McGowan JG, Rogers AL (2009) Wind energy explained: theory, design and application. 2nd edn. Wiley, Chippenham

Marty W, Sigrist T, Wyler D (2001) Temperature variations in automobiles in various weather conditions: an experimental contribution to the 
determination of time of death. Am J Forensic Med Pathol 22:215-219. doi:10.1097/00000433-200109000-00001

Matzarakis A, Rutz F, Mayer H (2007) Modelling radiation fluxes in simple and complex environments - application of the RayMan model. Int $\mathrm{J}$ Biometeorol 51:323-334. doi:10.1007/s00484-006-0061-8

Matzarakis A, Rutz F, Mayer H (2010) Modelling radiation fluxes in simple and complex environments: basics of the RayMan model. Int $\mathrm{J}$ Biometeorol 54:131-139. doi:10.1007/s00484-009-0261-0

McLaren C, Null J, Quinn J (2005) Heat stress from enclosed vehicles: moderate ambient temperatures cause significant temperature rise in enclosed vehicles. Pediatrics 116:e109-e112

Nakamura T, Yamaji T, Takayama K (2013) Effects of packaging and heat transfer kinetics on drug-product stability during storage under uncontrolled temperature conditions. J Pharm Sci 102:1495-1503. doi: $10.1002 / j p s .23486$

Null J (2012) Hyperthermia deaths of children in vehicles. [www.ggweather. $\mathrm{com} /$ heat]. Department of Geosciences, San Francisco State University

Ondrak J, Jones M, Fajt V (2015) Temperatures of storage areas in large animal veterinary practice vehicles in the summer and comparison with drug manufacturers' storage recommendations. BMC Vet Res 11:248

Reindl DT, Beckman WA, Duffie JA (1990) Diffuse fraction correlations. Sol Energy 45:1-7

Roberts KB, Roberts EC (1976) The automobile and heat stress. Pediatrics 58:101-104

Rugh J, Chaney L, Lustbader J, Meyer J, Rustagi M, Olson K, Kogler R (2007) Reduction in vehicle temperatures and fuel use from cabin ventilation, solar-reflective paint, and a new solar-reflective glazing. Paper presented at the SAE World Congress, Detroit, MI

Rugh J, Farrington R (2008) Vehicle ancillary load reduction project closeout report. National Renewable Energy Laboratory, Golden

Rupp RF, Vásquez NG, Lamberts R (2015) A review of human thermal comfort in the built environment. Energy Build 105:178-205. doi:10.1016/j.enbuild.2015.07.047

Schauberger G (1992) Anisotropic model for the diffuse biologicallyeffective irradiance of solar UV-radiation on inclined surfaces. Theor Appl Climatol 46:45-51
Schmalwieser AW, Schauberger G (2001) A monitoring network for erythemally-effective solar ultraviolet radiation in Austria: determination of the measuring sites and visualisation of the spatial distribution. Theor Appl Climatol 69:221-229

Schuliar Y, Savourey G, Besnard Y, Launey JC (2001) Diagnosis of heat stroke in forensic medicine: contribution of thermophysiology. Forensic Sci Int 124:205-208

Shannon Flournoy W, Wohl JS, Macintire DK (2003) Heatstroke in dogs: pathophysiology and predisposing factors. Compend Contin Educ Pract Vet 25:410-418

Shapiro Y, Rosenthal T, Sohar E (1978) Experimental heatstroke. Arch Intern Med 131:688-692

Smith GB, Gentle A, Swift PD, Earp A, Mronga N (2003) Coloured paints based on iron oxide and silicon oxide coated flakes of aluminium as the pigment, for energy efficient paint: optical and thermal experiments. Sol Energy Mater Sol Cells 79:179-197. doi:10.1016/S0927-0248(02)00410-5

Surpure JS (1982) Heat-related illness and the automobile. Ann Emerg Med 11:263-265

Szczyrbowski J, Dietrich A, Hartig K (1989) Bendable silver-based low emissivity coating on glass. Solar Energy Mater 19:43-53. doi:10.1016/0165-1633(89)90022-1

VDI 3789 Blatt 2 (1994) Umweltmeteorologie - Wechselwirkungen zwischen Atmosphäre und Oberflächen Berechnung der kurz- und der langwelligen Strahlung. Beuth Verlag, Berlin

Wattmuff JH, Charters WWS, Proctor D (1977) Solar and wind induced external coefficients for solar collectors. Int Rev Heliotechnique 2:56

WMO (2008) Guide to meteorological instruments and methods of observation vol WMO no 8, 7 edn. Secretariat of the WMO, Genf

Zhang G-S, Li T-T, Luo M, Liu J-F, Liu Z-R, Bai Y-H (2008) Air pollution in the microenvironment of parked new cars. Build Environ 43:315-319. doi:10.1016/j.buildenv.2006.03.019

Zhao Y, Zhang H, Arens EA, Zhao Q (2014) Thermal sensation and comfort models for non-uniform and transient environments, part IV: adaptive neutral setpoints and smoothed whole-body sensation model. Build Environ 72:300-308. doi:10.1016/j.buildenv.2013.11.004 